\title{
Nanotechnology for Health and Development by Gregor Wolbring
}

Correction to: Development (2006) 49(4), 6-15. doi:10.1057/palgrave.development. 1100309

Please note all references to disableism should read ableism.

In Wendy Harcourt's editorial of Development Volume 49 Number 4 on 'Big Science: individual hopes, collective risks', in the course of the editing process my editorial was corrected erroneously so that Gregor Wolbring's important point about 'ableism' was changed to being one on 'disableism'. I have personally apologized to Dr Wolbring as he himself stated in private correspondence to me this was extremely confusing to all of those people following his work on the rights of disabled people and who know that he is a strong advocate of 'ableism' as the correct term. Please see his Ableism and NBICS (15 August 2006) online http://www.innovationwatch.com/commentary_choiceisyours.htm.

The corrections to the Development 49.4 Editorial should therefore read:

'Gregor Wolbring opens up the conversation in his lead article on the promises and perils of nanotechnology and nano-bio-info-cogno-synbio (NBICS) for the global community when understanding disability (he speaks of "ableism")'.

'Rachel Hurst shows how deeply our prejudice (or what she refers to as disableism) is in relation to the search for the perfect'.

Given the importance of the issue Dr Wolbring has been asked to write a paper for a future issue of Development which he will adapt from a paper he has written on how ableism drives inequality and inequity and science and technology policy. 